\title{
Prospective Teachers' Metaphorical Conceptualizations of Learner
}

\author{
Ahmet Saban, Selcuk University, Faculty of Education, 42090 Konya, Turkey, asaban@selcuk.edu.tr
}

\begin{abstract}
This study explored the metaphorical images that prospective teachers in Turkey $(\mathrm{N}=2847)$ formulated to describe the concept of learner. Participants completed the prompt "A student is like . . because . . ." to indicate their conceptualizations of learner. Data was analyzed both qualitatively and quantitatively. Altogether 156 valid metaphorical images were identified and 11 main conceptual themes were developed. Also, significant associations were detected between participants' gender, class level, and program type and the 11 conceptual themes. Metaphors provide a potent cognitive device in gaining insight into prospective teachers' thinking and reasoning.
\end{abstract}

Keywords: Prospective teachers; Metaphorical conceptions of learner; Program type, gender, and class level differences; Phenomenological research

\section{Introduction and Purpose}

Mostly inspired by the work of Lakoff and Johnson (1980), currently a cognitive theory of metaphor has evolved, which considers metaphors as mental constructs that shape human thinking about the world and reality. From the standpoint of the cognitive theory, metaphors act as a lens, a screen, or a filter through which a subject is reviewed and become a mental model for thinking about a phenomenon in light of another. The metaphorical expression of "A student is like a white page", for instance, refers not just to what students are like, but indeed to what it is like to be a learner. Conducted within the framework of the cognitive theory of metaphor and having the Turkish socio-cultural context as a background, this study had the following four aims:

(1) What metaphorical images do prospective teachers use to describe the concept of learner?

(2) What conceptual themes (or categories) can be derived from these metaphorical images?

(3) Do the participants' gender, program type, and class level affect their conceptualizations of learner?

(4) What implications can be derived for teacher training?

\section{Conceptual Framework}

A review of the pertinent research literature on metaphors in education reveals a multitude of learning and teaching conceptions. Inbar (1996), for example, collected and categorized over 7000 metaphorical images of teacher, learner, principal, and school provided by 409 students and 254 educators. According to the results, about $18 \%$ of the educators perceived students as empty receptacles (e.g., student as jar, bottle, container, or cup) while only $7 \%$ of the students' own images came from this group. Again, about $10 \%$ of the educators' metaphors involved images of students as clay in the potter's hands (e.g., student as mud, toothpaste, chewinggum, or dough) while only $3 \%$ of the students' metaphors reflected this conception. Perhaps a more critical finding of the study was that about $33 \%$ of the students and $8 \%$ of the educators conceptualized learners as captive beings (e.g., student as slave, servant, prisoner, or trapped bird).

In the same way, Bozlk (2002) asked 49 first-year college students to create metaphors for themselves as learners at four points during an academic year. Altogether 35 well-articulated metaphors were collected, which then were categorized into the following four main groups: (1) Animal metaphors (37\%), i.e., student as snail, fish, lemming, duck, mule, cow, bird, mouse, cheetah, camel, donkey, squirrel, and sea cucumber; (2) Object metaphors (29\%), i.e., student as sponge, crayon, roller coaster, bump \& go toy, wrecking ball, tide, curtain, tornado, strainer, and computer program; (3) Human metaphors (26\%), i.e., student as toddler, kid eating candy, observer, entrepreneur, kid in a candy store, baby, child, hurdler, and person with Alzheimer's; and (4) Action metaphors (8\%), i.e., drying a counter, climbing a tree, and eating. Further analysis of the study findings reveled that students tend to come to higher education seeing themselves as passive learners, ready to soak up the teachers' knowledge. They are also concerned with retaining their information once they acquire it (e.g., person with Alzheimer's).

Recently, Saban, Kocbeker, and Saban (2007) explored 1142 teacher education students' metaphorical images of teacher by using the prompt "A teacher is like . . . because . . ." Altogether 64 valid personal metaphorical images were identified. Then, based on these images, 10 main conceptual themes for teacher were developed: (1) Teacher as knowledge provider (26.3\%), i.e., teacher as sun, candle, fruit tree, light, flower, computer, television, book, pen, spring, jug, fountain, rain, writer, and shopkeeper; (2) Teacher as molder (24.3\%), i.e., sculptor, painter, constructor, baker, potter, honeybee, cook, jeweler, tailor, carpenter, architect, miner, weaver, ironworker, contractor, technician, and mill; (3) Teacher as curer (1.8\%), i.e., doctor, medicine, and mechanic; (4) Teacher as superior authority (2.5\%), i.e., shepherd, ship captain, locomotive, and brain; (5) 
Teacher as change agent (0.5\%), i.e., fashion designer and scriptwriter; (6) Teacher as entertainer (1.8\%), i.e., actor/actress and stand-up comedian; (7) Teacher as counselor (8\%), i.e., parent, friend, psychologist, and companion; (8) Teacher as nurturer (9\%), i.e., gardener, farmer, soil, and chameleon; (9) Teacher as facilitator (18.6\%), i.e., compass, lighthouse, north star, flashlight, traffic signs, taxi driver, road map, torch, bridge, and ladder; and (10) Teacher as cooperative leader (7.3\%), i.e., tour guide, coach, and conductor.

Do prospective and experienced teachers differ in the way they think of teaching and learning? Martinez, Sauleda, and Huber (2001) analyzed the metaphorical images coming from 50 experienced elementary teachers and 38 fourth-year teacher education students. The findings were then analyzed according to three theoretical perspectives: (1) the behaviorist perspective, which perceives learning as a passive process of knowledge acquisition; (2) the cognitive perspective, which views learning as an individual process of schemata construction; and (3) the socio-cultural perspective, which conceives learning as an authentic participation in the activities of a social community. Results indicated that the majority of both experienced teachers $(57 \%)$ and prospective teachers $(56 \%)$ shared traditional metaphors depicting teaching and learning as transmission of knowledge (e.g., Learning is like a video camera which records the world.). About $38 \%$ of experienced teachers and $22 \%$ of prospective teachers expressed constructivist metaphors (e.g., Learning is like a detective who looks for things and into things.). While only $5 \%$ of the metaphors of experienced teachers conceived teaching and learning as a social process (e.g., Teaching is like a tourist guide who negotiates a route with the tourists.), $22 \%$ of prospective teachers' metaphors reflected this conceptual theme.

Do prospective teachers' metaphorical images of selves differ from those they have of their past elementary and current cooperating teachers? Saban (2004) investigated 363 exit level elementary teacher education students' metaphorical images of selves as future teachers and compared them to the ones they had of their both former elementary teachers and current cooperating teachers. Data for the study was gathered through the administration of a Likert-style questionnaire consisting of 20 metaphorical images of teacher (namely, shopkeeper, driver, jockey, technician, potter, doctor, mechanic, commander, judge, prison-guard, parent, baby-sitter, gardener, juggler, comedian, tool provider, compass, tour guide, coach, and conductor). These images were then grouped under two broad theoretical perspectives in education characterized as teachercentered perspective (the first 10 images) and student-centered perspective (the latter 10 images). According to the results, teacher candidates appeared to be less teacher-centered and more student-centered than their both former elementary teachers and current cooperating teachers. Also, female teacher candidates appeared to be less teacher-centered and more student-centered than their male peers in terms of their professional self-images.

\section{Method}

\section{Participants}

The participants for this study were 2847 teacher education students enrolled in six different study programs of the Faculty of Education of the Selcuk University in Turkey (see Table 1). Classroom Teaching (CT) students constituted the largest group (49\%), followed by English Teaching (ET) students (17.9\%); Social Studies Teaching (SST) students (9.8\%); Science Teaching (ST) students (8.9\%); Math Teaching (MT) students (7.5\%); and Computer \& Instructional Technologies (CIT) students (7\%). Altogether 1165 males (40.9\%) and 1682 females $(59.1 \%)$ participated in the study. The distribution of gender across the six different programs was as follows: $39.4 \%$ males and $60.6 \%$ females in the CT program; $26.1 \%$ males and $73.9 \%$ females in the ET program; $56.1 \%$ males and $43.9 \%$ females in the SST program; $32.9 \%$ males and $67.1 \%$ females in the ST program; $48.6 \%$ males and $51.4 \%$ females in the MT program; and $70.4 \%$ males and $29.6 \%$ females in the CIT program. Also, the distribution of participants in each class level was as follows: $31.8 \%$ first year students; $19.4 \%$ second year students; $25 \%$ third year students; and $23.8 \%$ fourth year students. Finally, the participants' ages ranged from 17 to 32 years ( $\mathrm{M}=20.48$ years, $\mathrm{SD}=1.76)$.

Table 1: Information about the participants.

\begin{tabular}{|l|l|l|l|l|l|l|l|}
\hline & CT & ST & CIT & ET & MT & SST & Total \\
& $f(\%)$ & $f(\%)$ & $f(\%)$ & $f(\%)$ & $f(\%)$ & $f(\%)$ & $f(\%)$ \\
\hline Male & $549(39.4)$ & $83(32.9)$ & $140(70.4)$ & $133(26.1)$ & $104(48.6)$ & $156(56.1)$ & $1165(40.9)$ \\
\hline Female & $845(60.6)$ & $169(67.1)$ & $59(29.6)$ & $377(73.9)$ & $110(51.4)$ & $122(43.9)$ & $1682(59.1)$ \\
\hline First year & $477(34.2)$ & $59(23.4)$ & $55(27.6)$ & $182(35.7)$ & $54(25.2)$ & $79(28.4)$ & $906(31.8)$ \\
\hline Second year & $231(16.6)$ & $66(26.2)$ & $39(19.6)$ & $72(14.1)$ & $68(31.8)$ & $76(27.3)$ & $552(19.4)$ \\
\hline Third year & $324(23.2)$ & $57(22.6)$ & $53(26.6)$ & $164(32.2)$ & $46(21.5)$ & $68(24.5)$ & $712(25)$ \\
\hline Fourth year & $362(26)$ & $70(27.8)$ & $52(26.1)$ & $92(18)$ & $46(21.5)$ & $55(19.8)$ & $677(23.8)$ \\
\hline Total & $1394(49)$ & $252(8.9)$ & $199(7)$ & $510(17.9)$ & $214(7.5)$ & $278(9.8)$ & $2847(100)$ \\
\hline
\end{tabular}

\section{Data Collection Process}


Data was collected through the use of the prompt "A student is like . . because . ." Simply, a blank piece of paper with this prompt on top of the page was distributed to the participants, asking them to complete it by focusing on a single metaphorical image. The participants were given about one class-hour (45 minutes) to write about a metaphorical image that represented their thinking best. This was because the researcher was mainly interested in the participants' immediate reactions to the student concept rather than their exhaustive essays on the topic. The resemblance between the metaphor topic (student) and the metaphor vehicle (source domain) was emphasized through the use of the word like. The relationship was further clarified through the use of the word because. In this way, participants were expected to make their implicit beliefs explicit.

\section{Data Analysis Process}

The analysis of the participants' metaphorical images encompassed the following five stages and actions.

\section{Coding and Elimination}

In the first stage, all the metaphorical images supplied by the participants were simply coded (such as dough, notebook, parrot, etc.). Also, those papers in which a metaphorical image was not clearly articulated were eliminated. For example, some participants simply did not write anything about the topic. Again, some participants mostly talked about the characteristics of effective or ineffective teachers, instead of introducing a metaphorical image. Albeit mentioning a metaphorical image, some participants did not provide any rationale for their metaphorical reasoning. Finally, some metaphors were fuzzy or hybrid, so they could not be placed under one clearly recognizable conceptual theme. So, altogether 137 papers were eliminated.

\section{Sample Metaphor Compilation}

In the second stage, the coded metaphorical images were scrutinized to choose a sample expression that represented each identified metaphorical image best. Hence, an alphabetical list of the 156 exemplar metaphorical images was produced as a reference point for the grouping of the images into certain categories.

\section{Sorting and Categorization}

The ultimate aim in the third stage was to abstract from the 156 exemplar metaphorical images the conceptual themes that they represented. Thus, each metaphorical image was analyzed to characterize its elements: (1) the topic (student), (2) the vehicle (the source domain to which the topic is compared), and (3) the ground (the nature of the relationship between the metaphor topic and the metaphor vehicle). So each metaphorical image was broken down into analyzable parts, looking for salient features and common elements. By using this inductive analysis technique, 11 major conceptual categories were identified, each of which encompassed those metaphoric images with similar emphasis.

\section{Establishing the Inter-Rater Reliability Rate}

Inter-rater reliability assesses the consistency of a coding system used in a research. Since the critical step of the data analysis process was the abstraction of the 11 generative categories and the classification of the 156 exemplar metaphorical images into them, an outside coder was also asked to sort the 156 images into the 11 conceptual themes. To estimate the inter-rater reliability rate, Miles and Huberman's (1994) formula (i.e., Reliability $=$ Agreement $/$ Agreement + Disagreement) was used. The final inter-coder agreement rate in qualitative data analysis is expected to approach or exceed $90 \%$. In the present study, the independent coder placed the metaphors of scapegoat, plant, pencil, water, treasure, and snowdrop under different categories than the researcher - i.e., Reliability $=150 / 150+6=0.96$.

\section{Analyzing Data Quantitatively}

In the last stage, all the study data was entered into the SPSS program to calculate frequencies (f) and percentages (\%) of the metaphorical images in each category as well as to compare the 11 conceptual themes across the participants' gender, class level, and program type.

\section{Results}

Altogether participants produced 156 well-articulated metaphors for "learner". CT students developed 141 metaphorical images; ST students articulated 79 metaphorical images; CIT students provided 71 metaphorical images; ET students generated 99 metaphorical images; MT students wrote 65 metaphorical images; and SST students mentioned 72 metaphorical images. The first 10 metaphorical images which were common among all participants included the following: (1) seedling (12.7\%), (2) flower (8.4\%), (3) dough (7.3\%), (4) white page (4.8\%), (5) seed (4.5\%), (6) soil (3.5\%), (7) mine (2.9\%), (8) clumsy stump (2.8\%), (9) flash disk/CD (2.1\%), and (10) computer (1.9\%). Out of 156, 30 metaphors were mentioned by only 2 participants while the rest 126 were represented by between 3 and 361 students. The mean student number per 
metaphor was about 18 . Accordingly, only 36 metaphorical images were mentioned by $18(0.6 \%)$ or more participants whereas the majority of them $(n=120)$ were represented by less than 18 students.

\section{Conceptual Categories}

\section{Student as Empty Vessel}

There were 526 students $(18.5 \%)$ and 24 metaphors $(15.3 \%)$ under this category and the following eight metaphors were dominant: (1) white page (4.8\%), (2) soil (3.5\%), (3) flash disk/CD (2.1\%), (4) computer $(1.9 \%)$, (5) field (1.7\%), (6) notebook (0.8\%), and (7) blackboard (0.7\%). Also, the metaphors of computer, flash disk/CD, notebook, soil, and white page were common among all the participants. Main characteristics of this category of metaphors include the following: (1) The student displays an empty brain (e.g., blackboard, box, cup, and white page). (2) The student's brain is unlimited (e.g., bag, bucket with a hole, computer, and hard disc). (3) The student accepts knowledge without any reservation (e.g., soil and trash can). (4) Learning is a process of accumulating knowledge (e.g., balloon, dam, and pool). (5) Learning is a process of storing knowledge (e.g., fridge, money box, sack, and storeroom). (6) Teaching is a process of depositing knowledge into the students' brains (e.g., bank account, flash disk/CD, and postbox). (7) Learning is furnishing of the mind with the teachers' knowledge and ideas (e.g., diary, field, notebook, and suitcase).

\section{Student as Knowledge Recipient}

There were 147 students $(5.2 \%)$ and 23 metaphors (14.7\%) under this category. Only one metaphor (i.e., sponge) was dominant, appealing to 20 students $(0.7 \%)$, and the metaphor of memory machine was common among all the participants. Main characteristics of this category of metaphors include the following: (1) The teacher is the main source of knowledge (e.g., root of a tree, sunflower, and TV viewer). (2) The student is assumed to be in need of knowledge (e.g., antenna, beggar, and poor person). (3) Knowledge has no practical value for the students (e.g., camel, donkey, memory machine, porter, snowball, and trolley). (4) Teaching is a one-way process of knowledge transmission (e.g., customer). (5) Learning is a process of observing and recording facts and events (e.g., camera, photographer, owl, tape recorder, and video camera). (6) Learning is a process of absorbing knowledge (e.g., blood-sucking insect, magnet, and sponge). (7) Learning is a process of digesting knowledge (e.g., cow and mill).

\section{Student as Reflector of Knowledge}

There were 101 students $(3.5 \%)$ and 11 metaphors (7\%) under this category. The metaphors of mirror $(1.6 \%)$ and parrot $(0.7 \%)$ were dominant and common among all the participants. Main characteristics of this category of metaphors include the following: (1) The main role of the student is to reflect the teacher's knowledge (e.g., mirror, moon, shadow, and star). (2) The student merely supplies what the teachers have loaded in his/her brain (e.g., parrot, printer, and printing press). (3) Knowledge is a sort of substance to be reflected by the students (e.g., echo and overhead projector). (4) Learning is a process of duplicating the teacher's knowledge (e.g., copy machine and plant).

\section{Student as Raw Material}

There were 644 students $(22.6 \%)$ and 25 metaphors $(16 \%)$ under this category. The following 10 metaphors were dominant: (1) dough (7.3\%), (2) clumsy stump (2.8\%), (3) stone/metal (1.8\%), (4) play dough $(1.5 \%),(5)$ construction $(1.3 \%),(6)$ water $(1.3 \%)$, (7) clay $(0.9 \%),(8)$ product $(0.8 \%)$, (9) unprocessed iron $(0.7 \%)$, and (10) grain of wheat $(0.7 \%)$. Also, the metaphors of clay, dough, grain of wheat, play dough, product, stone/metal, and clumsy stump were common among all the participants. Main characteristics of this category of metaphors include the following: (1) The student is a raw material (e.g., food ingredient, meatball, and play dough). (2) The teacher is a master (e.g., composition, lacework, and petroleum). (3) The student is expected to take all kinds of shapes (e.g., carpet, chewing gum, clay, plastic, and water). (4) Teaching is shaping students into a prescribed mold (e.g., construction, fabric, and unprocessed iron). (5) Teaching is producing students as socially useful products (e.g., book, dough, glass, poem, product, and stone/metal). (6) The teacher works to bring about cultural unity in the society (e.g., clumsy stump, mortar, and pencil). (7) There is a standardized curriculum for teachers and students to follow (e.g., computer program and grain of wheat).

\section{Student as Defective Being}

There were 51 students $(1.8 \%)$ and 12 metaphors $(7.7 \%)$ under this conceptual category, with no metaphor being common. Only one metaphor (i.e., puzzle) was dominant, appealing to 20 students $(0.7 \%)$. Main characteristics of this category of metaphors include the following: (1) The student is an intellectually defective being (e.g., draft of a book and labyrinth). (2) The student is a behaviorally defective being (e.g., patient). (3) The student is an emotionally defective being (e.g., schizophrenic). (4) The student is a problematic being (e.g., locked chest, multidimensional equation, password, puzzle, and tunnel). (5) The student is an unwanted being 
(e.g., street kid). (6) The student is in need of repair (e.g., broken car). (7) Teaching is treating students' flaws and deficiencies (e.g., virus).

\section{Student as Absolute Compliant}

There were 254 students $(8.9 \%)$ and 17 metaphors $(10.9 \%)$ under this category. Five metaphors were dominant: (1) race horse $(1.7 \%),(2)$ robot (1.6\%), (3) ship (0.7\%), (4) chameleon $(0.6 \%)$, and (5) slave $(0.6 \%)$. Also, four metaphors (puppet, race horse, robot, and slave) were common among all the participants. Main characteristics of this category of metaphors include the following: (1) The student is a captive being (e.g., cavy, prisoner, scapegoat, and slave). (2) The student is to obey all the rules and regulations without questioning the authority (e.g., soldier and wagon of a train). (3) The teacher decides about what and how to teach in the classroom (e.g., billiards ball, circus animal, passenger, robot, and ship). (4) The student acts according to the wills and desires of his/her teachers (e.g., chameleon, chess pawn, musical instrument, puppet, and sheep). (5) Learning is racing with peers (e.g., race horse).

\section{Student as Social Capital}

There were 36 students $(1.3 \%)$ and 7 metaphors $(4.5 \%)$ under this category, with no metaphor being common. Only one metaphor (i.e., investment) was dominant, appealing to 19 students $(0.7 \%)$. Main characteristics of this category of metaphors include the following: (1) The student is the guarantor of the future of the society in which s/he lives (e.g., investment, key, natural resources, and road to the future). (2) The teacher is the main vehicle to prepare students for the future of the society (e.g., hope). (3) The teacher acts as an architect of the society who works to change the mind setting of each student in the classroom (e.g., bridge and window to the future).

\section{Student as Significant Other}

There were 119 students $(4.2 \%)$ and 6 metaphors (3.8\%) under this category, with the metaphor of mine $(2.9 \%)$ being dominant and common among all the participants. Main characteristics of this category of metaphors include the following: (1) The student is a unique individual (e.g., iceberg and rainbow). (2) The teacher attends to the needs, interests, and characteristics of his/her students (e.g., island and ocean). (3) The most important job of the teacher is to expose the hidden talents of his/her students (e.g., mine and treasure).

\section{Student as Developing Organism}

There were 843 students $(29.6 \%)$ and 14 metaphors $(9 \%)$ under this category and the following four metaphors were dominant: (1) seedling (12.7\%), (2) flower (8.4\%), (3) seed (4.5\%), and (4) newborn baby $(1.6 \%)$. Also, five metaphors (flower, kitten, newborn baby, seed, and seedling) were common among all the participants. Main characteristics of this category of metaphors include the following: (1) The student is a growing being (e.g., apprentice and seed). (2) Learning is tied to the real life issues (e.g., chick, duckling, and newborn calf). (3) The teacher cares about the emotional well-being of each student in the classroom (e.g., fledgling, pet, seedling, son/daughter, and tortoise). (4) The most important job of the teacher is to support the growth of each student in the classroom (e.g., child, flower, kitten, and newborn baby).

\section{Student as Constructor of Knowledge}

There were 84 students (3\%) and 12 metaphors $(7.7 \%)$ under this category. Also, the metaphors of honeybee $(1.2 \%)$ and detective $(0.7 \%)$ were dominant, with the metaphor of honeybee being common among all the participants. Main characteristics of this category of metaphors include the following: (1) The student is an active being (e.g., honeybee and snowdrop). (2) Learning is a process of knowledge hunting (e.g., adventurer, explorer, fisherman, hunter, and scientist). (3) Learning is an individual activity of knowledge construction (e.g., construction worker and spider). (4) The student strives for meaning and understanding (e.g., detective, journalist, and philosopher)

\section{Student as Social Participant}

There were 42 students (1.5\%) and 5 metaphors (3.2\%) under this category, with no metaphor being common. Only one metaphor (i.e., ant) was dominant, appealing to 19 students $(0.7 \%)$. Main characteristics of this category of metaphors include the following: (1) Learning is a socio-cognitive process of meaning making (e.g., musician). (2) Students work and learn together, not in isolation from one another (e.g., ant). (3) The teacher acts as a cooperative leader in the classroom (e.g., actor/actress). (4) The teacher acts as a guide in the teaching-learning process (e.g., tourist and footballer).

\section{Effects of Program Type, Gender, and Class Level}




\section{Program Type Differences}

The $\chi^{2}$ analysis regarding program type was significant $\left(\chi^{2}(10, \mathrm{~N}=2.847)=32.055, p=0.000\right)$, indicating that elementary and secondary participants conceptualized learner with significantly different metaphorical images (see Table 2). Specifically, while elementary students produced more metaphors in the categories of student as empty vessel, reflector of knowledge, raw material, and significant other, secondary students generated more metaphors in the categories of student as knowledge recipient, defective being, and absolute compliant. The remaining four categories (namely, student as capital of society, developing organism, constructor of knowledge, and social participant) were represented equally.

Table 2: Distribution of 11 conceptual categories by program type (counts and columns percentages)

\begin{tabular}{|l|l|l|l|}
\hline $\begin{array}{l}\text { Conceptual category for } \\
\text { student }\end{array}$ & $\begin{array}{l}\text { Prospective elementary } \\
\text { teachers }(\mathrm{CT})(\mathrm{n}=1394) \\
f(\%)\end{array}$ & $\begin{array}{l}\text { Prospective secondary teachers (ST } \\
+\mathrm{CIT}+\mathrm{ET}+\mathrm{MT}+\mathrm{SST})(\mathrm{n}=1453) \\
f(\%)\end{array}$ & $\begin{array}{l}\text { Total }(\mathrm{n}=2847) \\
f(\%)\end{array}$ \\
\hline Developing organism & $407(29.2)$ & $836(30)$ & $643(29.6)$ \\
\hline Raw material & $339(24.3)$ & $305(21)$ & $526(18.5)$ \\
\hline Empty vessel & $274(19.7)$ & $252(17.3)$ & $254(8.9)$ \\
\hline Absolute compliant & $99(7.1)$ & $155(10.7)$ & $147(5.2)$ \\
\hline Knowledge recipient & $57(4.1)$ & $90(6.2)$ & $119(4.2)$ \\
\hline Significant other & $67(4.8)$ & $52(3.6)$ & $101(3.5)$ \\
\hline Reflector of knowledge & $59(4.2)$ & $42(2.9)$ & $84(3)$ \\
\hline Constructor of knowledge & $38(2.7)$ & $46(3.2)$ & $51(1.8)$ \\
\hline Defective being & $19(1.4)$ & $32(2.2)$ & $42(1.5)$ \\
\hline Social participant & $18(1.3)$ & $24(1.7)$ & $36(1.3)$ \\
\hline Social capital & $17(1.2)$ & $19(1.3)$ & \\
\hline Pearson chi-square $\chi^{2}(10, \mathrm{~N}=2.847)=32.055, p=0.000$ & & \\
\hline
\end{tabular}

\section{Gender Differences}

The $\chi^{2}$ analysis regarding gender was also significant $\left(\chi^{2}(10, \mathrm{~N}=2.847)=23.845, p=0.008\right)$, indicating that males and females conceptualized learner with significantly different metaphorical images (see Table 3 ). Specifically, males produced more metaphors in the categories of student as empty vessel, knowledge recipient, raw material, and defective being than females who in turn generated more metaphors in the categories of student as absolute compliant, significant other, and developing organism. The remaining four categories (namely, student as reflector of knowledge, capital of society, constructor of knowledge, and social participant) were represented equally.

Table 3: Distribution of 11 conceptual categories by gender (counts and columns percentages)

\begin{tabular}{|l|l|l|l|}
\hline Conceptual category for student & $\begin{array}{l}\text { Male }(\mathrm{n}=1165) \\
f(\%)\end{array}$ & $\begin{array}{l}\text { Female }(\mathrm{n}=1682) \\
f(\%)\end{array}$ & $\begin{array}{l}\text { Total }(\mathrm{n}=2847) \\
f(\%)\end{array}$ \\
\hline Developing organism & $305(26.2)$ & $538(32)$ & $843(29.6)$ \\
\hline Raw material & $273(23.4)$ & $371(22.1)$ & $644(22.6)$ \\
\hline Empty vessel & $250(21.5)$ & $276(16.4)$ & $526(18.5)$ \\
\hline Absolute compliant & $99(8.5)$ & $155(9.2)$ & $254(8.9)$ \\
\hline Knowledge recipient & $65(5.6)$ & $82(4.9)$ & $147(5.2)$ \\
\hline Significant other & $44(3.8)$ & $75(4.5)$ & $119(4.2)$ \\
\hline Reflector of knowledge & $41(3.5)$ & $60(3.6)$ & $101(3.5)$ \\
\hline Constructor of knowledge & $32(2.7)$ & $52(3.1)$ & $84(3)$ \\
\hline Defective being & $24(2.1)$ & $27(1.6)$ & $51(1.8)$ \\
\hline Social participant & $21(1.8)$ & $21(1.2)$ & $42(1.5)$ \\
\hline Social capital & $11(0.9)$ & $25(1.5)$ & $36(1.3)$ \\
\hline Pearson chi-square $\chi^{2}(10, \mathrm{~N}=2.847)=23.845, p=0.008$ & & \\
\hline
\end{tabular}

\section{Class Level Differences}

The $\chi^{2}$ analysis regarding class level was significant too $\left(\chi^{2}(10, \mathrm{~N}=2.847)=43.675, p=0.000\right)$, indicating that entry and exit level participants conceptualized learner with significantly different metaphorical images (see Table 4). Specifically, entry students produced more metaphors in the categories of student as reflector of knowledge, defective being, absolute compliant, and constructor of knowledge than their exit level 
peers who in turn generated more metaphors in the categories of student as empty vessel and developing organism. The remaining five categories (namely, student as knowledge recipient, raw material, significant other, capital of society, constructor of knowledge, and social participant) were represented equally.

Table 4: Distribution of 11 conceptual categories by class level (counts and columns percentages)

\begin{tabular}{|l|l|l|l|}
\hline Conceptual category for student & $\begin{array}{l}\text { Entry level }(1 \mathrm{st}+2 \mathrm{nd} \text { year) } \\
\text { students }(\mathrm{n}=1459) f(\%)\end{array}$ & $\begin{array}{l}\text { Exit level (3rd + 4th year) } \\
\text { students }(\mathrm{n}=1388) f(\%)\end{array}$ & $\begin{array}{l}\text { Total }(\mathrm{n}=2847) \\
f(\%)\end{array}$ \\
\hline Developing organism & $410(28.1)$ & $433(31.2)$ & $843(29.6)$ \\
\hline Raw material & $325(22.3)$ & $319(23)$ & $644(22.6)$ \\
\hline Empty vessel & $238(16.3)$ & $288(20.7)$ & $526(18.5)$ \\
\hline Absolute compliant & $164(11.2)$ & $90(6.5)$ & $254(8.9)$ \\
\hline Knowledge recipient & $72(4.9)$ & $75(5.4)$ & $147(5.2)$ \\
\hline Significant other & $59(4)$ & $60(4.3)$ & $119(4.2)$ \\
\hline Reflector of knowledge & $58(4)$ & $43(3.1)$ & $101(3.5)$ \\
\hline Constructor of knowledge & $56(3.8)$ & $28(2)$ & $84(3)$ \\
\hline Defective being & $33(2.3)$ & $18(1.3)$ & $51(1.8)$ \\
\hline Social participant & $26(1.8)$ & $16(1.2)$ & $42(1.5)$ \\
\hline Social capital & $18(1.2)$ & $18(1.3)$ & $36(1.3)$ \\
\hline Pearson chi-square $\chi^{2}(10, \mathrm{~N}=2.847)=43.675, p=0.000$ & & \\
\hline
\end{tabular}

\section{Discussion}

This study investigated prospective teachers' metaphorical images of learner. Several major understandings have emerged out of this research.

First, while metaphors can act as basic mental models for organizing one's knowledge of the world, some complex and abstract phenomena may require many different metaphors to represent them fully. The wide range of metaphorical images in this study, for example, reveals multiple realities of student (as empty vessel, raw material, absolute compliant, social participant, etc.) and no single metaphor alone appears to capture all of the complexities of the learner phenomenon. The main reason for this multitude of metaphors is because ". . metaphors are selective. They represent a part, but not the whole, of the phenomena they describe" (Weade \& Ernst, 1990, p. 133). Consequently, the 11 conceptual themes with their common characteristics may provide fresh lenses through which the learner phenomenon can be understood from different viewpoints.

Second, the metaphorical images collected throughout this study offer important insights into prospective teachers' thinking about the concept of learner. For example, unlike the three most dominant conceptual themes (student as developing organism (29.6\%), raw material (22.6\%), and empty vessel (18.5\%)), there were also those that were not very popular (namely, student as defective being $(1.8 \%)$, social participant $(1.5 \%)$, and social capital $(1.3 \%))$. While the conceptual themes of student as defective being and social capital represent in some way the teacher-centered approach, the third less-favored conceptual theme (i.e., social participant) is an extension of the student-centered perspective in education. Thus, it appears from the analysis that the socio-cognitive view of learning is by no means absent in the Turkish prospective teachers' thinking. The same presumption could also be maintained for the theme of student as constructor of knowledge (representing the cognitive view of learning), which covered only $3 \%$ of the participants' metaphorical images. This understanding could simply imply an urgent need for teacher educators in Turkey to take a closer look at the current teacher training programs and adjust them accordingly.

Third, various factors (e.g., gender, being an entry or exit level student, or majoring in elementary or secondary education) appear to influence how prospective teachers conceptualize learner. For example, in comparison to their secondary peers, more elementary teacher trainees in the present study visualized learner as empty vessel, reflector of knowledge, raw material, and significant other. Also, while entry level teacher candidates generated more images in the theme of student as absolute compliant, more exit level students viewed student as developing organism. Again, females generated more metaphorical images related to the themes of student as developing organism and significant other while males produced more metaphors in the categories of student as empty vessel and defective being.

Fourth, a closer examination of the participants' metaphorical images indicate that they gather around four major clusters, each of which also corresponds well to one of the four major philosophical viewpoints (as outlined by Oxford et al., 1998) that have shaped educational thought all the way through the centuries. The first cluster, i.e., cultural transmission (27.2\%), encompasses three of the 11 conceptual themes, (namely, student as empty vessel, knowledge recipient, and reflector of knowledge), all viewing the teacher as a gatekeeper who transmits to the students the cultural heritage of society. Metaphors falling into this perspective conceive learning as a passive process of knowledge acquisition. The second cluster, i.e., social order (34.6\%), 
encompasses four of the 11 conceptual themes (namely, student as raw material, defective being, absolute compliant, and social capital), all viewing the teacher as a social engineer who molds students for the needs of society. Metaphors falling into this perspective conceive learning as a process of adapting to the prevalent societal norms and expectations. The third cluster, i.e., learner-centered growth (36.7\%), encompasses three of the 11 conceptual themes, (namely, student as significant other, developing organism, and constructor of knowledge), all viewing the teacher as a facilitator of personal growth and development. Metaphors falling into this perspective conceive learning as an individual process of schemata construction. The fourth cluster, i.e., social reform $(1.5 \%)$, includes only one conceptual theme (namely, student as social participant), viewing the teacher as a social catalyst in the creation of a democratic community. Metaphors falling into this perspective conceive learning as an authentic participation in the activities of a social community.

\section{Implications for Teacher Education}

One important goal of teacher education programs is to facilitate teacher trainees in developing their professional knowledge. On entry to teacher training programs, teacher education students tend to bring with them a reasonably well-developed set of personal beliefs about what constitutes effective teaching and learning. "With this in mind, a thoughtful teacher educator might ask: What are the preconceptions about teaching and learning held by our students?" (Clark, 1988, p. 7). The activity of metaphor generation in this respect can serve as a valuable pedagogical tool for teacher educators in urging their teacher trainees to examine, understand, and ultimately modify their preconceived beliefs of teaching and learning. Hence, in different stages of becoming a teacher (e.g., entry stage, practicum stage, or induction stage), teacher candidates could be asked to provide their perceptions of various educational concepts via metaphor. After examining their own metaphorical images and becoming more aware of their own beliefs, prospective teachers can then be offered alternative metaphors for personal consideration. In this way, a process of change could be initiated through awareness of own images, comparison with alternatives, and identification of new images that would be more consistent with the images of selves. That is to argue that through the generation and discussion of own metaphors (as reflective and renewal tools), prospective teachers can come to understand their professional selves they have developed over the years as well as the selves they want (and are able) to become in the upcoming years. In accomplishing all of these worthwhile professional undertakings, metaphor appears to be the most potent cognitive device.

\section{References}

Bozlk, M. (2002). The college student as learner: Insight gained through metaphor analysis. College Student Journal, 36, 142-151.

Clark, C. M. (1988). Asking the right questions about teacher preparation: Contributions of research on teaching thinking. Educational Researcher, 17, 5-12.

Inbar, D. (1996). The free educational prison: Metaphors and images. Educational Research, 38, 77-92.

Lakoff, G. \& Johnson, M. (1980). Metaphors we live by (Chicago, IL: University of Chicago Press).

Martinez, M. A., Sauleda, N., \& Huber, G. L. (2001). Metaphors as blueprints of thinking about teaching and learning. Teaching and Teacher Education, 17, 965-977.

Miles, M. B. \& Huberman, A. M. (1994). Qualitative data analysis (Thousand Oaks, CA: Sage).

Oxford, R. L., Tomlinson, S., Barcelos, A., Harrington, C., Lavine, R. Z., Saleh, A., \& Longhini, A. (1998). Clashing metaphors about classroom teachers: Toward a systematic typology for the language teaching field. System, 26, 3-50.

Saban, A. (2004). Prospective classroom teachers' metaphorical images of selves and comparing them to those they have of their elementary and cooperating teachers. International Journal of Educational Development, 24, 617-635.

Saban, A., Kocbeker, B. N., \& Saban, A. (2007). Prospective teachers' conceptions of teaching and learning revealed through metaphor analysis. Learning and Instruction, 17, 123-139.

Weade, R. \& Ernst, G. (1990). Pictures of life in classrooms, and the search for metaphors to frame them. Theory into Practice, 29, 133-140. 